\title{
Erratum to: Glutamate-glutamine and GABA in brain of normal aged and patients with cognitive impairment
}

\author{
Dandan Huang ${ }^{1} \cdot$ Dan Liu $^{2} \cdot$ Jianzhong Yin $^{2} \cdot$ Tianyi Qian $^{3} \cdot$ Susan Shrestha $^{1}$. \\ Hongyan $\mathrm{Ni}^{2}$
}

Published online: 9 March 2017

(C) European Society of Radiology 2017

Erratum to: Eur Radiol

DOI 10.1007/s00330-016-4669-8

The original version of this article, published on 13 December 2016, unfortunately contained mistakes. The following corrections have therefore been made to the original publication:

The online version of the original article can be found at doi:10.1007 /s00330-016-4669-8.

\footnotetext{
Hongyan Ni

nihyan@sina.com

1 Department of Radiology, First Central Clinical College, Tianjin Medical University, Tianjin 300070, China

2 Department of Radiology, Tianjin First Center Hospital, Tianjin 300192, China

3 MR Collaborations NE Asia, Siemens Healthcare, Beijing 100102, China
} 
The presentation of Fig. 3 of this article was incorrect. The corrected Fig. 3 is given below.
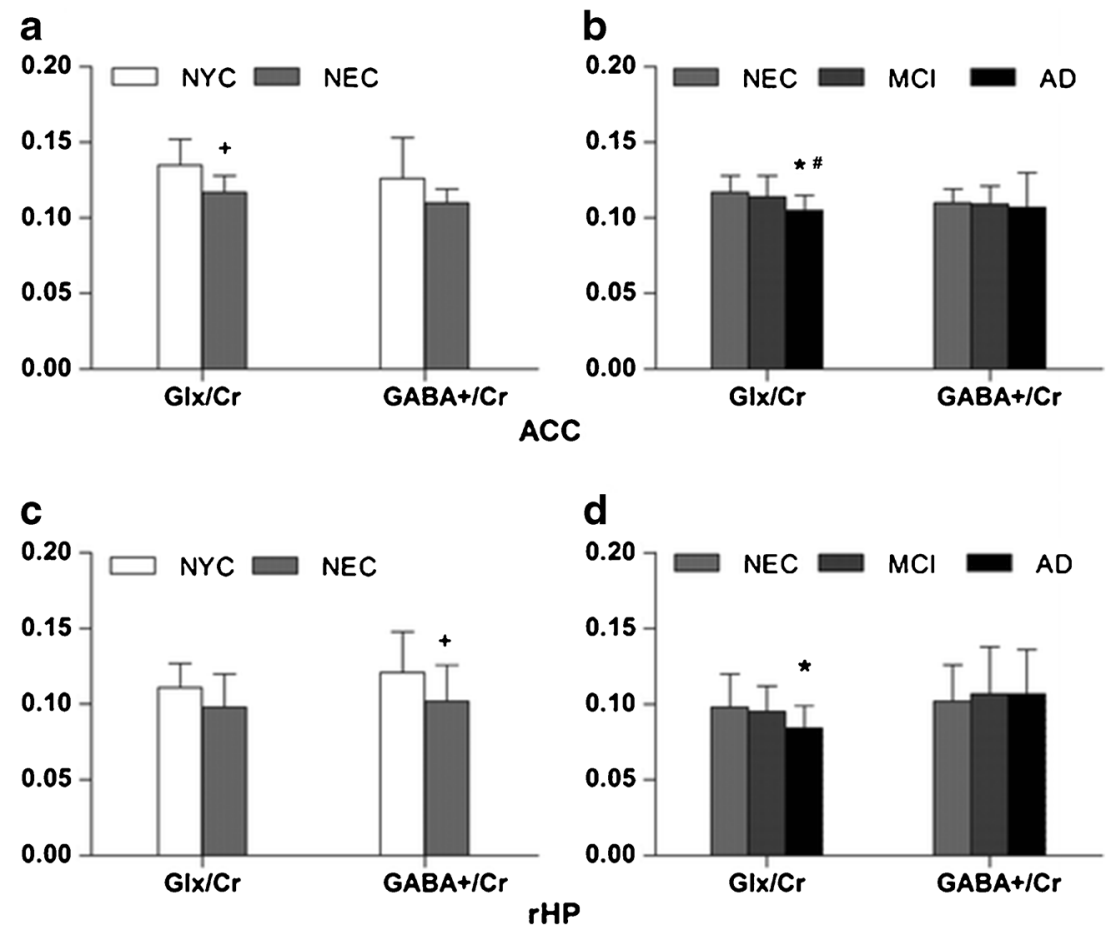

Fig. 3 Histogram of results of metabolite levels in the four groups. Glx/Cr and GABA+/Cr levels in ACC (a, b) and rHP (c, d). $+\mathrm{p}<0.05, \mathrm{NYC}$ vs. NEC; $* \mathrm{p}<0.05$, AD relative to $\mathrm{NEC} ; \# \mathrm{p}<0.05$, AD relative to $\mathrm{MCI}$

Additionally, we have also changed the wording of the Acknowledgments from "This study has received funding by the National Natural Science Foundation of China (grant no. 30870713), the Tianjin Research Program of Application Foundation, Advanced Technology (grant no. 13JCQNJC14400), the Tianjin Science and Technology Support Project (grant no. 15ZCZDSY00520), and the Tianjin Bureau of Public Health (grant no. 15KG134)" to
"This study has received funding from the National Natural Science Foundation of China (Grant No. 30870713), Tianjin Science and Technology Support Projects (Grant Nos. 16 J C Y B J C 25900 , 15 Z C Z D S Y 00520 , a n d 13JCQNJC14400), and the Tianjin Bureau of Public Health Projects (Grant No.15KG134)". 